\title{
DE FORMAÇÃO E DESENVOLVIMENTO DE COLEÇ̃̃ES PARA GESTÃO DE ESTOQUES DE INFORMAÇÃO: UM PANORAMA DA MUDANÇA TERMINOLÓGICA NO BRASIL
}

\author{
FROM COLLECTION DEVELOPMENT TO MANAGEMENT INFORMATIONAL STORAGE: \\ A LANDSCAPE OF THE TERMINOLOGICAL CHANGE IN BRAZIL
}

\author{
Elisa Cristina Delfini Correa ${ }^{1}$ \\ Luana Carla de Moura dos Santos ${ }^{2}$
}

\section{RESUMO}

Análise do panorama da mudança terminológica de Formação e Desenvolvimento de Coleções para Gestão de Estoques Informacionais na literatura da área e nos cursos de Biblioteconomia no Brasil. Propõe uma reflexão sobre a necessidade de atualização de conceitos para a atividade, demonstrando o atual estado-da-arte do uso do termo "Gestão de Estoques de Informação" em artigos de periódicos eletrônicos da área publicados entre 2000 e 2012 através de sua ocorrência nos títulos, resumos e palavras-chave dos artigos e da avaliação da oferta de disciplinas com a mesma nomenclatura nas escolas de Biblioteconomia Brasileira, analisando suas ementas a fim de identificar novas práticas. Conclui que a literatura não apresenta artigos com o descritor "Gestão de Estoques de Informação", o que indica uma possível desconexão com a gestão na organização de acervos. Da mesma forma, de um universo de 37 escolas, apenas 5 cursos brasileiros posuem disciplina com essa nomenclatura. Porém, a análise de suas ementas revela a manutenção dos conceitos clássicos de formação e desenvolvimento de coleções. Estes dados indicam a necessidade de uma mudança paradigmática teórico-prática diante das demandas da sociedade contemporânea.

PALAVRAS-CHAVE: Formação e desenvolvimento de coleções. Gestão de estoques de informação. Ensino de Biblioteconomia.

\begin{abstract}
Analysis of the landscape of terminological shift Collection Development to Management Informational Storage in the literature and librarianship courses in Brazil, offering a reflection on the need of updating concepts. Analysis of the use of the term "Management Informational Storage" in articles published journals of the area between 2000 and 2012 through its occurrence in the titles, abstracts and keywords of. Evaluation of offering courses with the same nomenclature in schools of librarianship in Brazil, analyzing their menus in order to identify new practices. The literature shows no articles with the descriptor " Management Informational Storage", which indicates a possible disconnection with management in the organization of collections. Likewise, from an universe of 37 schools, only 5 courses Brazilians has disciplines under that name. However, analysis of their menus reveals the maintenance of the classical concepts of training and development of collections. These data indicate the need for a theory and practice paradigm shift to attend the demands of contemporary society.
\end{abstract}

KEYWORDS: Collection development. Management informational storage. Librarianship teaching.

\footnotetext{
${ }^{1}$ Docente do Departamento de Biblioteconomia e Gestão da Informação - Universidade do Estado de Santa Catarina, Centro de Ciências da Educação. E-mail: elisacorrea61@ gmail.com

${ }^{2}$ Bibliotecária Analista de sistemas. E-mail: luana-moura@ hotmail.com

Recebido em: 20/11/2013 - Aceito em: 12/11/2014
} 


\section{INTRODUÇÃO}

O termo "formação e desenvolvimento de coleções" é utilizado para definir as atividades voltadas ao acervo e datam das décadas de 1980 e 1990 alguns dos mais importantes textos sobre o tema. No Brasil, dentre os autores que se dedicaram a estudar o assunto, destacam-se Waldomiro Vergueiro e Nice Figueiredo, cujas contribuições foram fundamentais para apresentar uma visão sistêmica de um conjunto de atividades administrativas com a finalidade de orientar o trabalho do bibliotecário voltado aos acervos.

A partir dessas leituras, a formação bibliotecária passou a refletir suas atividades sob um ponto de vista metódico, visando à necessidade de planejar ações para transformar suas tarefas anteriormente realizadas de modo intuitivo ou a partir de uma visão "artística" da profissão ${ }^{3}$, para um enfoque mais organizado e sistêmico.

Esses autores constituem-se no principal marco teórico sobre o qual baseiam-se, desde então, as atividades voltadas ao gerenciamento de coleções. No entanto, o rápido desenvolvimento da informação eletrônica desencadeou expressivas mudanças aos acervos das bibliotecas. Durante a década de 1990, passou-se a discutir como administrar o acervo a partir dos "impactos" das novas tecnologias de comunicação e informação (NTCI), especialmente sob o ponto de vista da mudança do paradigma "posse X acesso" aos itens de informação nas bibliotecas.

Todo este cenário resultou em uma proposta diferenciada de formação profissional, voltada às questões tecnológicas demandadas pela Sociedade da Informação culminando, já na entrada do século XXI, em alterações curriculares nos cursos de graduação em Biblioteconomia. Esse movimento gerou também a criação de cursos de graduação com nomenclaturas diferenciadas, que se propunham a formar um profissional mais adequado em tempos de informação eletrônica.

O foco desta análise recai sobre o ensino da disciplina Formação e Desenvolvimento de Coleções que, embora houvesse sido incluída tardiamente no currículo mínimo do curso de bacharelado em Biblioteconomia e Documentação no Brasil, precisou ser rapidamente atualizada diante do fenômeno da informação eletrônica.

Diante dessa necessidade, algumas escolas de Biblioteconomia no Brasil reformularam seus currículos apresentando uma ainda incipiente mudança terminológica da disciplina de Formação e Desenvolvimento de Coleções (FDC) para "Gestão de Estoques Informacionais", ou "Gestão de Estoques de Informação" (GEI). Para entender melhor essa mudança, segue uma breve análise retrospectiva do contexto da formação em Biblioteconomia no Brasil do final do século passado, que apresenta um cenário de novas ideias e conceitos introduzidos tanto na formação quanto na atuação do bibliotecário nesse

\footnotetext{
${ }^{3}$ São interessantes os textos de Gaston Litton, publicados na década de 1970, que retratam o bibliotecário enquanto "guardião, companheiro e amigo dos livros" e a biblioteca como "a morada dos livros". A Biblioteconomia, segundo este autor, seria uma "arte", além de uma ciência.
} 
período, com enfoque especial dado à disciplina objeto desta investigação.

\section{FDC E O ENSINO DE BIBLIOTECONOMIA NO BRASIL NAS ÚLTIMAS DÉCADAS DO SÉC. XX: CENÁRIO DE MUDANÇAS SIGNIFICATIVAS}

As últimas duas décadas do século $\mathrm{XX}$ foram prodigiosas em termos de estruturação do ensino de Biblioteconomia no Brasil. Em primeiro lugar, menciona-se a aprovação da realização do curso de bacharelado em 4 anos e do novo currículo mínimo (ambos na década de 1980), subdividido em três grupos de "matérias": Fundamentação Geral, Instrumentais e Formação Profissional (SOUZA, 2009, p.126).

Neste currículo, aprovado em 1982, foi introduzida a disciplina Formação e Desenvolvimento de Coleções que, segundo Vergueiro (1993, p.20) trazia como ementa "princípios e políticas de seleção: formas, recursos procedimentos e legislação para aquisição; princípios e técnicas de avaliação de coleções; conservação de coleções; política de expansão da biblioteca". Esta disciplina fazia parte do núcleo de disciplinas técnicas e, ainda segundo Vergueiro (id. 1993, p.20):

\section{Seus objetivos são assim delineados: capacidade de formular princípios e métodos e empregar técnicas para formação, desenvolvimento e avaliação das coleções, visando à sua adequação aos usuários, e compreensão da necessidade de conservação dos diversos suportes físicos do conhecimento e de tratamento adequados a cada tipo, de acordo com sua natureza.}

O mesmo autor apontou que a chegada de estudos sobre a formação e o desenvolvimento de coleções no Brasil, refletiu o resultado de um movimento verificado através de literatura especializada estrangeira ${ }^{4}$ e afirma em sua análise que a introdução da disciplina no currículo mínimo em 1982 representou um grande avanço nos estudos sobre o tema no país.

A década de 1990 foi cenário de turbulências teóricas no campo da Biblioteconomia, principalmente por conta das "negociações" com a emergente Ciência da Informação brasileira e das rápidas mudanças tecnológicas. Começam a ficar evidentes algumas dificuldades com o caráter interdisciplinar necessário ao profissional da informação a fim de lidar com seu objeto.

Tais dificuldades são evidenciadas especialmente a partir do discurso originado pela então FID - Federação Internacional de Documentação - que apresentava a figura do

\footnotetext{
${ }^{4} \mathrm{O}$ texto de Vergueiro apresenta os principais modelos teóricos estrangeiros, citando por exemplo: James C.Baugman (1979) e G.Edward Evans (1979).
} 
Moderno Profissional da Informação (MIP) como o perfil ideal para o bibliotecário trazendo novas implicações para o ensino de Biblioteconomia no Brasil. Durante a década de 1990, intensificou-se o debate também entre os países do Mercosul, quando começa a ser delineado um ensino de Biblioteconomia com características transdisciplinares, a fim de promover a formação de profissionais com ênfases especialmente voltadas a questões de "gerência, de agregação de valor, de geração de um novo produto e de organização e socialização do conhecimento" (GUIMARÃES, 2009, p.31).

Para tentar dar conta dessas mudanças, e na tentativa de responder à LDB (Lei de Diretrizes e Bases) de 1996, deu-se início uma nova série de discussões para a formulação de novos currículos nos vários níveis de ensino no Brasil (SOUZA, 2009). Como resultado, foi realizada uma nova reestruturação do ensino de Biblioteconomia brasileiro, a partir de outra proposta de diretrizes curriculares que subdividia o curso agora em quatro áreas: Fundamentos Teóricos da Biblioteconomia, Organização e Tratamento da Informação, Recursos e Serviços de Informação e Gestão de Unidades e Serviços de Informação.

Surge então uma nova proposta de diretrizes curriculares do Ministério da Educação e Cultura (MEC) como fruto de todas as discussões entre profissionais e formadores da área nos últimos anos da década de 1990. Na proposta, apresentada por Valentim (2000, p.16), o termo utilizado para os estudos sobre coleção foi então reduzido para "Normas para Desenvolvimento de Coleções" e incluído na área Recursos e Serviços de Informação. Contudo, prevaleceu a designação do nome Formação e Desenvolvimento de Coleções, utilizada tanto pelas escolas de Biblioteconomia, quanto na literatura específica da área.

A nomenclatura "Gestão de Estoques Informacionais" (GEI) começa a ser utilizada nas reformulações curriculares de alguns cursos de graduação a partir dos anos 2000. No entanto, não é comum encontrar a menção ao termo nem na literatura da área e nem como nomenclatura da disciplina na maioria dos cursos de graduação país afora.

Aparentemente não estão ainda fundamentados os aspectos teóricos dessa mudança terminológica através da publicação de artigos no Brasil, o que dificulta o entendimento da construção de argumentos que justifiquem essa transição.

Este fato conduz à necessidade de uma reflexão acerca do uso do termo Gestão de Estoques de Informação especialmente a partir de suas implicações na tentativa da construção de uma mudança paradigmática que se reflita não apenas no ensino, mas também na prática do bibliotecário no contexto da sociedade da informação. Para tal, este artigo apresenta uma breve reflexão a respeito dos novos termos, sua necessidade e aplicabilidade. 


\section{CONCEITOS DE GESTÃO DE ESTOQUES DE INFORMAÇÃO: UMA REFLEXÃO PARA OS TEMPOS ATUAIS}

Diante do contexto da sociedade altamente conectada digitalmente, a realidade da geração, uso e fluxo da informação apresenta-se hoje de maneira essencialmente diferente, dentro e fora das bibliotecas. Disto decorre a necessidade de repensar a visão estratégica da organização de acervos de unidades de informação, sob uma perspectiva gerencial e social igualmente adequada ao novo perfil do frequentador real ou potencial das bibliotecas.

Assim, a reflexão a seguir propõe uma atualização do termo Formação e Desenvolvimento de Coleções para Gestão de Estoques de Informação, tanto em seus aspectos administrativos quanto na relação do bibliotecário e da biblioteca com seu públicoalvo.

\subsection{Gestão}

São evidentes as conexões entre as áreas da Biblioteconomia e da Administração, ficando muito claras suas aplicações especialmente nas questões gerenciais de unidades de Informação. A gestão é um termo intrinsecamente administrativo que significa, nesse contexto, um "conjunto de funciones y técnicas integradas, de ejecucíon simultânea, que deben aplicar de forma necesaria los cuadros directivos, como responsables del trabajo de otros, para lograr que la organización a la que pertencen funcione y pueda alcanzar los propósitos que persigue" (GARCIA-REYES, 2007, p. 12).

O propósito final de um processo de gestão de bibliotecas é sempre o alcance de um nível de qualidade e excelência em produtos e serviços de informação. Sendo assim, as coleções dessas unidades estão invariavelmente incluídas nesse ambiente organizacional e, portanto, alvo de atenção gerencial, pois "quando se tem a intenção de construir uma biblioteca de qualquer tipo, em qualquer época ou local, necessita-se de uma política sistemática de formação do acervo" (MCGARRY, 1999, p. 112).

De forma geral, "gestão" pressupõe planejamento, acompanhamento, avaliação. Portanto, gerenciar acervos significa mais que localizar, agrupar e conservar. Significa:

- Definir e aplicar critérios de seleção, aquisição, avaliação e preservação para disponibilização, buscando atingir níveis de excelência;

- Traçar metas de desenvolvimento e expansão do acervo, levando em consideração os objetivos da instituição, as demandas informacionais existentes e a serem criadas, o contexto político, social e econômico local, nacional e mundial; 
- Planejar atividades meio e fim, captando recursos humanos e financeiros suficientes para sua execução e para atingir as metas propostas;

- Lembrar que o lucro é sempre um objetivo a ser atingido, mesmo que não corresponda necessariamente a valores financeiros;

- Pressupõe a existência de um gestor: profissional responsável, qualificado para exercer liderança em todo o processo envolvendo os recursos e políticas administrativas mencionadas.

A figura do gestor é fundamental para o sucesso no trabalho com acervos. Holanda e Nascimento (2010) afirmam que o bibliotecário gestor de unidades de informação deve desenvolver habilidades e competências com aportes em um conjunto de conhecimentos administrativos e tecnológicos de disciplinas formativas que perpassam conteúdos como modelos organizacionais, planejamento e tomada de decisões, economia e políticas de informação, dentre outras que o capacitem a gerenciar uma biblioteca com vistas à oferta de produtos e serviços de qualidade.

De acordo com Scharnberg e Strehl (2012) planejar acervos significa fixar objetivos e detalhar etapas para atingi-los, prevendo e alocando os recursos necessários, acompanhando a execução e avaliando resultados. O planejamento através da política de estoques de informação é uma das principais atividades desse gestor. Sua atuação estratégica é essencial desde o diagnóstico que precede sua formulação e passa por todas as etapas de sua concretização, num processo cíclico e interminável de negociação que envolve diferentes níveis de tomadas de decisão (MACIEL; MENDONÇA, 2000, p. 17-18).

O propósito principal das atividades desse gestor é suprir demandas de um público específico através da oferta de material informativo, o que leva ao conceito de estoque, apresentado a seguir.

\subsection{Estoques de Informação}

Barreto (2000) conceitua estoque de informação como "toda a reunião de estruturas de informação. Estoques de informação representam, assim, um conjunto de itens de informação organizados (ou não), segundo um critério técnico, dos instrumentos de gestão da informação e com conteúdo que seja de interesse de uma comunidade de receptores".

A ideia de estoque remete ao conceito de materiais cuja aquisição e manutenção envolvem recursos que possuem valores e por isso não devem em hipótese alguma permanecer ociosos. Segundo Moreira (1998, p.1), é preciso lembrar que "estoque é investimento e conta como parte do capital da empresa".

Sendo assim, os estoques de informação devem circular constantemente, devem ser dinâmicos e atrativos. A gestão desses estoques deve visar à criação e o atendimento de 
demandas de informação com o fim de torná-los lucrativos diante dos objetivos da instituição que mantém a unidade de informação, passando por revisões contínuas e periódicas, pois tem como finalidade última o atendimento de demandas específicas. Devem ser constantemente renovados e divulgados para que não fiquem parados nas estantes, ao contrário, devendo ser "consumidos" a fim de gerar conhecimento a um público cada vez mais exigente e autônomo.

\subsection{Interagente da informação}

Um último conceito que vale a pena discutir aqui é o interagente da informação em contraposição ao de usuário da informação. Na Biblioteconomia o termo "usuário" (uma tradução do inglês "user") tem sido utilizado há muitos anos para designar o utilizador da biblioteca enquanto o "indivíduo que necessita de informação para o desenvolvimento de suas atividades" (SANZ CASADO, 1994, p.19, citado por COSTA et.al, 2010,p.15).

Buonacore (1976) define usuário de biblioteca como aquele que habitualmente utiliza um ou mais de seus serviços de maneira mais intensa e assídua, inclusive os de traduções, resumos analíticos, bibliografias especializadas, etc.

Dentro ou fora das bibliotecas, no contexto da sociedade conectada onde cada usuário é um potencial autor de conteúdo na rede Internet, o perfil deste é marcado por um alto nível de interatividade tanto com a informação em si, quanto com seus mediadores. Surge a necessidade de repensar o termo usuário:

O termo "usuário", tão utilizado nos estudos da "interatividade", deixa subentendido que tal figura está à mercê de alguém hierarquicamente superior, que coloca um pacote a sua disposição para uso (segundo as regras que determina). Isso posto, este trabalho defende o abandono desse problemático conceito e preferirá adotar o termo "interagente" (uma tradução livre de interactant, não raro utilizado em pesquisas de comunicação interpessoal), que emana a própria ideia de interação. (PRIMO, 2005, p.2/16).

É possível perceber esforços neste sentido na Biblioteconomia, e uma das formas de através do uso do termo "cliente" sem, contudo, que haja um consenso sobre sua pertinência. Lunardelli (2007) comenta que alguns estudiosos da Ciência da Informação atribuem ao termo "usuário" uma acepção mais passiva do que "cliente", indicando uma valorização apenas do prestador de serviço enquanto que o usuário seria apenas alguém que o utiliza. Por outro lado, "cliente" daria uma conotação mais ativa, indicando aquele que deseja e/ou busca especificamente um produto ou serviço.

Após uma análise léxica dos dois termos, a autora conclui que não é possível afirmar a existência de um termo correto, apenas a busca de uma melhor adequação deste às condições de cada situação.

Numa tentativa de utilizar um termo que melhor retrate o público-alvo dos serviços de bibliotecas, surge como proposta deste artigo o termo "interagente". Neste, a ideia do 
frequentador real ou potencial ultrapassa a de um simples receptor do produto ou serviço, e aponta para uma visão mais especializada de um público com demandas específicas e com características mais participativas não apenas no uso dos itens informacionais, mas também na própria geração, etiquetagem e fluxo da informação propriamente dita.

O termo de onde a palavra é originada, ou seja, "interação", reflete mais apropriadamente a relação bibliotecário/leitor/pesquisador que acontece no ambiente da biblioteca já no contato inicial: "a interação é um processo de influência mútua. Na biblioteca ela ocorre quando o usuário busca uma informação solicitando o auxílio do bibliotecário." (CHAGAS, ARRUDA, BLATMANN, 2000, p.1).

Porém, na sociedade atual, esta deve acontecer em níveis muito mais elevados. As unidades de informação atuais, bem como seus gestores precisam atentar para o fato de que hoje os "usuários" são também co-autores de boa parte da informação, interagindo em seus processos de criação e fluxo, especialmente no ambiente digital.

Através de ferramentas wiki e de processos como a folksonomia, por exemplo, a participação do usuário tem-se intensificado tornando-o cada vez mais autônomo, e os resultados desse fenômeno também são percebidos nos ambientes das unidades de informação mais tradicionais como as bibliotecas.

Torna-se ainda mais apropriado conceito de "interatividade" que vem gradualmente substituindo o de "interação" e que, segundo Silva (2000, citado por LIMA, SOUZA, DIAS, 2012, [s/n]), foi:

\footnotetext{
Incorporado inicialmente pela Psicologia e Sociologia e, posteriormente, pela Informática, na tentativa de cobrir algumas especificações ausentes no conceito de "interação"[...] Os fundamentos da interatividade estão ligados a pelo menos três binômios: participação-intervenção (resposta autônoma, criativa e não-prevista na audiência), bidirecionalidade-hibridação (dimensão semiótica, abrir fronteiras) e potencialidade-permutabilidade (disponibilidade instantânea a todas as possibilidades, percepção de obras inacabadas), sendo considerados aspectos distintos, mas que dialogam entre si e não são independentes.
}

Os binômios apresentados por Silva estão presentes na relação leitor/pesquisador e informação não apenas no ambiente digital, mas também podem ser adaptadas e aplicadas na relação com a informação disponibilizada e mediada em bibliotecas. Por isso, faz-se necessário atrair o público freqüentador e utilizador dos estoques de informação para uma parceria mais efetiva dentro do ambiente da biblioteca.

Belluzzo (2010) aponta também para a necessidade de um bibliotecário que atue como mediador e que seja também um interagente a fim de que possa desempenhar suas atividades também através da comunicação eletrônica.

No entanto, para que essa prática se concretize no dia-a-dia das bibliotecas, é necessária uma formação acadêmica que contemple uma mudança paradigmática. O estudo 
apresentado a seguir apresenta um panorama que demonstra as possibilidades de uma nova visão nas escolas brasileiras a partir da concepção da gestão de estoques de informação nos cursos de Biblioteconomia.

\section{GESTÃO DE ESTOQUES DE INFORMAÇÃO: O USO DA NOVA TECNOLOGIA NO CAMPO CIENTÍFICO E ACADÊMICO}

O uso de novos termos para designar tanto os acervos propriamente ditos quanto as atividades voltadas a sua organização já podem ser percebidos na literatura da área, em substituição ao tradicional "formação e desenvolvimento de coleções", ainda que timidamente.

Com a finalidade de conhecer o estado-da-arte da utilização de novas terminologias voltadas à formação e desenvolvimento de acervos no campo teórico da área, foram realizadas buscas exploratórias em periódicos eletrônicos da área de Ciência de Informação (CI) e Biblioteconomia brasileiras durante os anos de 2000 a 2012, e nas páginas web das Universidades que oferecem cursos de graduação em Biblioteconomia no Brasil.

Para a pesquisa nos artigos científicos, buscou-se o uso do termo "gestão de estoques informacionais" em títulos, resumos e palavras-chave em onze periódicos eletrônicos ${ }^{5}$ e em todos eles o resultado foi "nenhum item recuperado", verificando-se sua inexistência nas revistas brasileiras de Biblioteconomia e Ciência da Informação.

Já a busca com o termo "estoques de informação" mostrou-se melhor sucedida. Foram recuperados cinco artigos que utilizaram o termo em seus conteúdos e/ou títulos na Revista DataGramaZero, um artigo na Revista Informação e Informação, dois na Revista Ciência da Informação, e um na Revista Informação e Sociedade, totalizando nove artigos.

Por outro lado, a busca do termo "Gestão de Estoques de Informação" não obteve nenhum item recuperado. Disso se depreende o fato de que o termo "estoque de informação" apresenta-se como a única alternativa de descritor para recuperação de textos sobre o tema, sendo inexistentes (até o término da pesquisa) menções do termo Gestão de Estoques de informação na literatura da área no Brasil.

Pode-se concluir preliminarmente que a vinculação do termo "gestão" e "estoques de informação" ainda não está estabelecida na literatura, o que leva ao questionamento quanto ao entendimento e aplicação de novos termos que designem a prática de atividades profissionais voltadas à gestão das coleções.

Parece ser ainda necessário solidificar a visão de que tais atividades tratam-se de atividades de gestão. Assim, os aspectos administrativos do processo parecem ainda não estar

\footnotetext{
5 Ciência da Informação, Perspectivas em Ciência da Informação, Transinformação, Encontros Bibli, Informação e Informação, Emquestão, Informação e Sociedade, Revista ACB, RDBCI, Revista IberoAmericana de Ciência de Informação e Biblionline.
} 
suficientemente claros na definição dos termos que identificam as práticas, dificultando também o entendimento do papel e de uma postura do bibliotecário enquanto gestor.

\section{DE FDC PARA GEI: NOVAS NOMENCLATURAS NOS CURSOS BRASILEIROS}

Além da fraca presença de termos diferenciados nos periódicos científicos, é possível observar também uma ainda tímida utilização de novas nomenclaturas para designar as disciplinas dos cursos de graduação em Biblioteconomia no Brasil. Com a finalidade de conhecer o panorama da oferta dessas disciplinas, foi realizada uma pesquisa nas páginas web de trinta e sete cursos existentes no Brasil ${ }^{6}$.

Deste universo, não foi possível acessar o elenco das disciplinas de quatorze cursos que não se encontravam disponíveis nos sites, e também não responderam aos emails enviados pelas pesquisadoras. Verificou-se ainda que um dos cursos não oferecia a disciplina em questão. Dos restantes, constatou-se que apenas cinco apresentavam títulos que continham os termos "gestão" (ou gerenciamento) e "estoque (ou acervo) informacional" em substituição ao termo "Formação e Desenvolvimento de Coleções" quais sejam: Gerenciamento de Acervos Informacionais, Gestão de Estoques Informacionais (em dois cursos), Gestão de Acervos Informacionais e Gestão da Coleção ${ }^{7}$.

Apenas três das ementas das cinco disciplinas estavam disponíveis online para análise, não revelando diferenças substanciais no sentido da aproximação de um novo paradigma como sugerido neste artigo. Ainda são muito fortes os conceitos de "formação e desenvolvimento de coleções" herdados das décadas de 1980 e 1990, abordando questões relativas a princípios e formas de seleção e aquisição, metodologias de avaliação e estudos de comunidade e de usuários. A política de gestão de estoques aparece em apenas uma das ementas.

Como diferença principal, percebe-se o uso do termo "gestão" no lugar de "formação e desenvolvimento" e "estoques" ao invés de acervos ou coleções, em alguns casos. Apesar de representarem um ponto de partida importante, as ementas não avançam no real significado dessas mudanças, nem mesmo aprofundam o que pode ser considerado como gestão aplicada às coleções de bibliotecas enquanto estoques de informação.

\section{CONSIDERAÇÕES FINAIS}

A visão administrativa das atividades de formação e desenvolvimento de coleções pode ser considerada como a principal justificativa da evolução terminológica dos termos

\footnotetext{
${ }^{6}$ Levantamento realizado a partir do site da ABECIN (www.abecin.org.br)

${ }^{7}$ Faculdades Integradas Coração de Jesus (FAINC), Fundação Escola de Sociologia e Política de São Paulo (FEPESP) e Universidade do Estado de Santa Catarina (UDESC), Pontifícia Universidade Católica de Campinas (PUC) e Universidade Federal da Paraíba (UFP), respectivamente.
} 
utilizados para designar as atividades voltadas ao cuidado com os acervos em unidades de informação. Discutir esta temática trata-se de um esforço para construir um referencial teórico-prático que caminhe não apenas para uma visão conceitual dessa atividade tão essencial no fazer bibliotecário, mas também, e principalmente, de buscar estabelecer um novo paradigma de atuação profissional voltado a uma visão administrativa e, portanto, mais profissionalizada e compatível com a sociedade atual.

A Biblioteconomia carece de um escopo teórico que reflita sobre suas práticas mais tradicionais, e a gestão de estoques de informação é uma das áreas em que isso se faz necessário. A partir da experiência acadêmica e da divulgação científica, será possível aplicar e adaptar conceitos e atividades de gestão que se reflitam na atuação profissional dedicada ao estoque de unidades de informação, criando uma nova mentalidade mais adequada às demandas contemporâneas.

O bibliotecário que atuar sob essa perspectiva, será capaz de desenvolver suas atividades a partir de um planejamento estratégico com base em uma política de coleções diferenciada, pensando os estoques em termos de vantagem competitiva diante de outros tipos de unidades de informação, questionando: o que temos a oferecer? O que mais podemos oferecer? Como oferecemos? Como divulgamos? Quanto circula nosso estoque e porque? Que metas podemos atingir para desenvolver e incrementar a qualidade da oferta e aumentar a demanda?

Esse profissional deverá também relacionar-se com seu público enquanto "interagente": para conhecê-lo melhor e ser competente em criar estratégias de alcance de novos grupos, a fim de buscar sua participação nos processos de seleção, aquisição e avaliação dos estoques, criando um ambiente favorável para a comunicação e aprendendo a lidar com críticas, elogios e sugestões.

Também será capaz de diversificar seus estoques, através do contínuo aprendizado e conhecimento de fontes informacionais em seu sentido mais amplo: pessoas, instituições, livros, revistas, periódicos, obras de referência, multimídia.

Proverá acesso físico e eletrônico às fontes relevantes a públicos diferenciados. Para isso, saberá que é essencial trabalhar em rede e estabelecer parecerias, buscar recursos externos, implantar cultura de colaboração e intercâmbio.

Porém, mudanças paradigmáticas não acontecem da noite para o dia: demandam estudos e trabalhos árduos, suscitam debates, reflexões e muitas negociações. Significa dizer que a simples mudança de nomenclatura não representa necessariamente a mudança paradigmática efetivada nem na teoria e nem na prática. Por isso, há necessidade de discutir o assunto com muito mais intensidade. Significa dizer que estamos apenas no início. 


\section{REFERÊNCIAS}

BELLUZZO, R.C.B. O profissional da informação na era do conhecimento: mediadores e interagentes? São Paulo, 2010. Slides de apresentação no Seminário de Biblioteconomia e Ciência da Informação.

BUONACORE, Domingo. Diccionario de Bibliotecología. 2.ed.aum. Buenos Aires: Ediciones Marymar, 1976.

CHAGAS, J. ; ARRUDA, S.; BLATMANN, U. Interação do usuário na busca de informações. Disponível em: <http://www.ced.ufsc.br/ ursula/papers/interacao.html>. Acesso em: 10 nov. 2013.

FIGUEIREDO, N.M. Desenvolvimento e avaliação de coleções. Brasília: Thesaurus, 1998.

GARCIA-REYES, C. J. Gestíon de unidades de informacíon. In: VERGUEIRO, W.; MIRANDA, A.C.D.(orgs). Administração de unidades de informação. Gramado: FURG, 2007. Cap. 1, p. 11-34.

GUIMARÃES, J.A.C. O Profissional da informação sob o prisma de sua formação. In: VALENTIM, M.P. (org.) Profissionais da informação: formação, perfil e atuação profissional. São Paulo: Polis, 2000. Cap. 2, p. 53-69.

HOLANDA, C.; NASCIMENTO, A. Bibliotecário: gestor das unidades de informação. In: ENCONTRO REGIONAL DOS ESTUDANTES DE BIBLIOTECONOMIA, DOCUMENTAÇÃO E CIENCIA E GESTÃO DA INFORMAÇÃO DA REGIÃO SUL, 12 ., 2010, Porto Alegre. Anais Eletrônicos... Porto Alegre: UFRGS, 2010. Disponível em: <http://rabci.org/rabci/node/127>. Acesso em: 09 jul. 2012.

LANCASTER, F.W. Avaliação de serviços de bibliotecas. Brasília: Briquet de Lemos, 1996.

LIMA, I.F, SOUZA, R.R.; DIAS, G.A. Interatividade e usabilidade em bibliotecas digitais no processo ensino-aprendizagem. DGZ, v.13, n.3, jun. 2012. Disponível em: <http://www.dgz.org.br/jun12/Art_03.htm>. Acesso em: 10 nov.2013.

LUNARDELLI, R.S.A. Usuários ou clientes de bibliotecas? Uma reflexão do ponto de vista da lexicologia. Disponível em:

<http://www.ofaj.com.br/textos_conteudo.php?cod=134>. Acesso em: 10 nov. 2013.

MACIEL, A.C.; MENDONÇA, M.A.R. Bibliotecas como organizações. Rio de Janeiro: Interciência, 2000. 
McGARRY, K. O conceito dinâmico da informação: uma análise introdutória. Brasilia: Briquet de Lemos/Livros, 1999.

MOREIRA, A.D. Administração da produção e operações. 3. Ed. Roteiro adaptado. Disponível em:

$<$ http://www.google.com.br/url?sa=t\&rct=j\&q=\&esrc=s\&source=web\&cd=1\&ved=0CE4QFj AA\&url=http $\% 3 \mathrm{~A} \% 2 \mathrm{~F} \% 2 \mathrm{Fwww}$. grupos.com.br\%2Fgroup $\% 2 \mathrm{Ffacear}$ engenharia\%2FMessa ges.html\%3Faction\%3Ddownload\%26year\%3D10\%26month\%3D5\%26id\%3D12748191812 15281\%26attach\%3DCONTROLE\%2520ESTOQUE_DM.doc\&ei=NEH4T8aZLYi08ATbw qX4Bg\&usg=AFQjCNHIBcQiIuhA3qptsfqmrn1oJjucYQ\&sig2=Wx4PN6GRtMw1fnFPSMo 09Q>. Acesso em: 07 jul 2012.

PRIMO, A.. Enfoques e desfoques no estudo da interação mediada por computador. Limc, n. 45, 2005. Disponível em:

<http://smeduquedecaxias.rj.gov.br/nead/Biblioteca/Forma\%C3\%A7\%C3\%A3o\%20Continu ada/Tecnologia/cibercultura/Enfoques $\% 20 \mathrm{e} \% 20$ desfoques $\% 20$ no $\% 20$ estudo $\% 20 \mathrm{da} \% 20$ intera \%C3\%A7\%C3\%A3o\%20mediada\%20por\%20computador.pdf>. Acesso em: 10 nov. 2013.

SCHARNBERG, J.M.R.; STREHL, L. Introdução à política de desenvolvimento de coleções como atividade de planejamento bibliotecário. 2012. Slides de aula da disciplina Pesquisa e Desenvolvimento de Coleções. Disponível em:

<http://www.slideshare.net/leticia.strehl/2-desenvolvimento-de-colees-poltica>. Acesso em: 10 nov. 2013

SOUZA, F.C. O ensino da biblioteconomia no contexto brasileiro: século XX. 2. ed. Revista. Florianópolis: UFSC, 2009.

VALENTIM, M.P. (org.) Profissionais da informação: formação, perfil e atuação profissional. São Paulo: Polis, 2000.

VERGUEIRO, W.de C.S. Desenvolvimento de coleções: uma nova visão para o planejamento de recursos informacionais. Brasília, Ciência da Informação, v.22, n.1, 1993.

\section{Como citar este documento:}

CORREA, Elisa Cristina Delfini; SANTOS, Luana Carla de Moura dos. De formação e desenvolvimento de coleções para gestão de estoques de informação: um panorama da mudança terminológica no Brasil. Revista Digital de Biblioteconomia e Ciência da Informação, Campinas, SP, v. 13, n. 2, p. 342-354, maio/ago. 2015. ISSN 1678-765X. Disponível em: 〈http://periodicos.bc.unicamp.br/ojs/index.php/rdbci/article/view/8634631>. Acesso em: 31 maio 2015. 